\title{
A CLASSIFICATION METHOD FOR JAPANESE SIGNS USING MANUAL MOTION DESCRIPTIONS
}

\author{
Hisahiro ADACHI and Kazuo KAMATA
}

\author{
Department of Infounation Science, Utsumomiya University, \\ Ishii-makh, Utmmomiya, 321, IAPAN

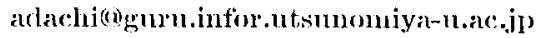

\begin{abstract}
SUMMARY In this paper, we propose a dassification mollool for signs in fapaneye bign language (JSI,). The methesel is based on the similarity between manual motion descriptions (MMDs) of signs. M MIDs alde the verbal descriptions of signs. 'The measure of similarily between M MDs is derived from their bonesest common subsernenes (L,Cs) of MMJs. By computing fealure vectors of 1 properties from a finte sel of MMl)s aud plotting them in the n-dimensional lindidean space, the similarity between signs can be regated as an internal anghe between the vectors. The result of onr experiment is that the signilicant sign fandies can be oistained.
\end{abstract}

\section{INTRODUCTION}

Stokon (1960) is the first linguist to deal with the? structure of signs in the same way as thate of oral words. He noted that there were thee kinds of parameters in describing thesign in Amerien Sign Language (ASL) as follows: (1) the location of the signe relative to the body, (2) the land-shape of hands involved in articulating the sign and, (3) the movement of hands. Other lingujsts (Friednan 1977, Batison 1978) latve clained that a fouth parameter is obligatory, that is, the spatial oricutation of the hands relative to the boly. In Japanese Sign langunge (JSib), a fow linguists ('lanokenni 1979, Kancla 1982) took the similal approaches.

Thus, we noed to spectly the location, hand-shape, movement and orientation of the hands to describe the sign. Furthermore, it is interesting to mote that at change in only one of the significant elements in handshape, location, orientation and movement of ten results in changing the meaning (ex., antonym, synonyur). The motation systems proposed by linguists can provide a very detailed and broader representation to describe signs. It is, however, not easy to transform the sign into the notation. For this reason, it is too cost 10 collect a large amount of sign data.

Consider, for example, a minimal pair in the novement as shown in l'ig.t.

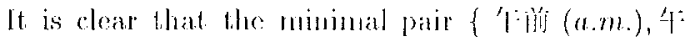
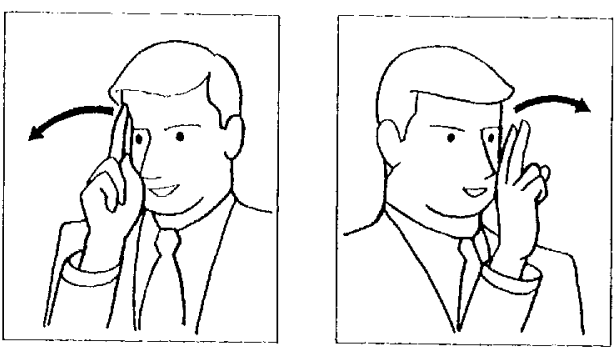

Fig 1: The Minimal Pair of Signs ('Fiof (a.m.), F後 (p.m.))

後 $(p, m)$.$\} means the antonym semantically and repre$ sents l.he symmetry visnally. 'Typical sign dictionary consists of illustrations or photographs and the verbal deseriptions, we called the descriptions manual motion descriplions (MMDs) represented as text, written in natural language.

It cau be considered that a MMD represents information extracted from a series of the manual notions of the signt. It is not difficult to find the synunetey of signs by the contrist between two MM1)s. For cxantple, the contrast of words fi (right) and ti: (left) can be

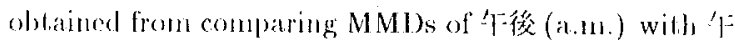
後 (p.m.) as follows.

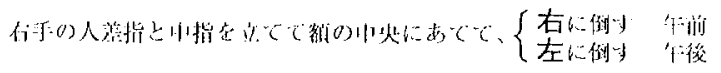

We deseribe a classification method for sigus using mathematical techniques based on the similarity bet.ween MMIs. 


\section{DATA STRUCTURES FOR MMDS}

This section describes the remarkable claracteristics of MML and a transformation method derived from them. The method moans that MMDs can be transformed into the n-dimensional foalune vectors.

\subsection{The Remarkable Characteristics of MMDs}

MMDs moan a kind of the verbal descriptions of the sign, which are written in Japanese langulage and has remarkable characteristics as follows:

- MMDs have unore consiraintis on syntactic palierns and words than general Iapranese sentences, In other words, there are some kind of syntactic palterns in MMDs.

- In Japanese, synonyus are often marked with the common kanji-characters. lior example, each set of words $A=\{$ 们乎，尘看，酒丁: $\}, B=\{$ 親指，

人指, 中指,染指,小指 \} has a common postlix kanji-character $\mathrm{F}$ or fub and sone kinds of semantic groups are constuncted by them such as

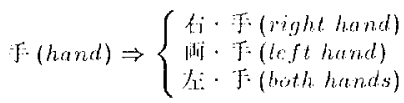

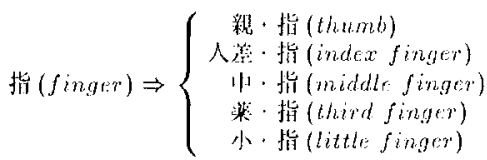

Thus, the combination of hanji-characters means semantic concatenation. Sato (1992) las also pointod out them in his paper.

\subsection{Transformation into Feature Voctors}

To represent the distribution of words mathematically, it is convenient to considered as points in the n-dimensional Fuclidean space. The condinates of points can be given as the n-dimensional feature vectors. Then, an intertal angle between the vectors can be considered as the sinilarity between the words. In this case, properties of the feature vectors need to many points of view. (i.e., word frequency, part of speech, co-occurence relation, and so on). In pattern recognitions, the same approaches lave made use of pecoguning pictures and letters. Therefore, we also select this approach which is signs are plotted in the n-dimensional Euclidean space, Foature vectors can be obtained by constructing a finite stale intomaton accepting MMDs as follows.

It is well known that finite state antomata recognizo finite state languages (see Alo, A.V., et al. 1974). If a class of palterns can be described in a linite stanc language, a fintite state antomaton can be constructed to recognize MMDs described this class of patterns.

\section{Example.2.1}

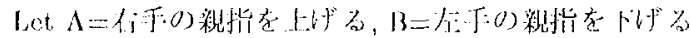

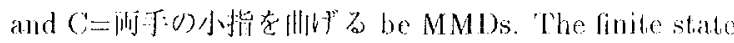
transition diagram of a antomaton accepting the set of MMD is shown in Fig. 2.2 .

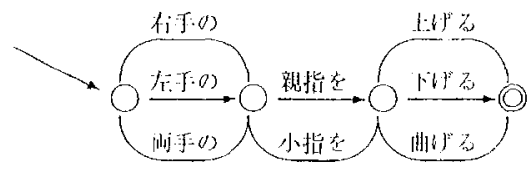

Fig 2: A finte: State Transition Diagram

Then, a regular expression derived from the above diagram is shown the following.

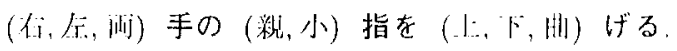

Fach kanji- or kana-character of the above regular expression can be considered as properties on the foature vectors for the sign. The fenture vectors for the sign derived from MMDs are slown in fable 1.

\begin{tabular}{|c|c|c|c|c|c|c|c|c|c|c|c|c|c|c|}
\hline & 位 & $y_{i}$ & , tint & J & (l) & 䘽 & 小 & 指 & 5 & $\mathrm{t}$ & & |ll| & 1) & 2 \\
\hline$\Lambda$ & 1 & 0 & 0 & 1 & 1 & 1 & 0 & 1 & 1 & 1 & () & () & 1 & 1 \\
\hline B & () & 1 & () & 1 & 1 & 1 & 0 & 1 & I & 0 & 1 & 0 & 1. & 1 \\
\hline O & () & 0 & 1 & 1 & 1 & () & 1 & 1 & I. & 0 & (1) & 1 & 1 & 1 \\
\hline
\end{tabular}

Table 1: The feature vectors derived from MMD

Thus, the signs can be represented as 14 -dimensional feature vectors, which can be defined as but vectors $E$ $[0,1]$.

lurthermore, we can find a kind of syntactic patiem

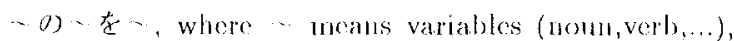
and $\theta)(n o)$ and $($ wo mean case markers. 


\section{SIMILARITY BEIWEEN SIGNS}

This section describes low a similarity between signs is computed. 'To compute similarity, we introduced the longest-common-subsequence function (ICS).

\subsection{Similarity between MMDs}

The result of the previons discussions can bo sult marized as follows:

1. Sinnilatity bedween lwo signs can be considered as sinilarity between two MMDs.

2. When describing signs mathenatically, it is conveweent to regard them as points or feature vectors in the n-dimensional linclitenu space. The similarity moasure betwent two signs is considered as an angle of two vectors.

3. If a finte state autemala acepting MNDs an be constuched, properties of feature vectors an be placed all chatacters constructing MMIs.

Jet $A=\left(a_{1}, a_{2}, \ldots, a_{n}\right)$ and $B=\left(b_{1}, b_{2}, \ldots, b_{n}\right) b_{0}$ n-dimensional feature vectors of signts. Thern, the similarity measure between sigus, denoted by $S^{\prime}(A, B)$, can be defined as follows:

IJEF.1:The Similarity between feature Vectors

$$
\begin{gathered}
S(A, B)=\cos ^{2} \theta=\frac{(A, B)^{2}}{\|A\|^{2}\|B\|^{2}} \\
(0 \leq S(A, B)<1)
\end{gathered}
$$

where $(A, B)$ is the inner product of vectors $A$ and $B$, and can be compulcol as follows:

$$
(A, B)=-\sum_{k=1}^{n} u_{k} b_{k}
$$

$\|A\|^{2}$ is the squared huclidean norm of vector $A$ and can be compuned as follows:

$$
\|A\|^{2}=(\sqrt{(A, A)})^{2}=\left(\sqrt{\sum_{k=1}^{n} a_{k}^{2}}\right)^{2}-\sum_{k=1}^{n} a_{k}^{2}
$$

Namely, $\|A\|^{2}$ an be computed as the sum of $a_{i}=$ I in vector $A .(A, B)$ can be compulued as the sun of $a_{i} \wedge b_{i}=1$ in feature vectors $\Lambda$ and $\mathrm{B}$

Recall the feature vecters of lable 1 in the last sece t.ion. $\|A\|^{2}$ an be devined ats a lenguth of $\mathrm{MM}$ M) related to vector $A$. In the same way, $(A, B)$ can be delined as a length of a longest common subsequence of $\mathrm{MMI}$ )s related to vectors $\Lambda$ and B. We shatl discuss il in detail.

\subsection{Longest Common Subsequenco}

$A$ subseculene of a fiven string is any string obbained by deleding zero or more symbols from the given string. A longest common subsequence (LCS) of two string's is a subsecquener of both that is as long as any other common subsequence.

An LCS means that the number of matehing chatr. acters contsidering the chancter onder constraint. fion example, if $\mathrm{X}=$ abebdab and $\mathrm{Y}=$ bdcaba, them an bos of $X$ and $Y$ is beba, and has length 4 as shown in big. 3. The other lies of $\mathrm{X}$ and $\mathrm{Y}$ are bdab and beab, and also have length 4

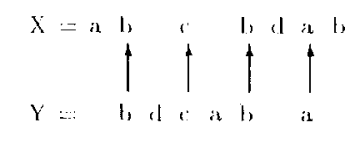

Fig 3: An LCS of $\mathrm{X}$ and $\mathrm{Y}$

Let. $A=a_{1} a_{2} \ldots a_{m}$ and $B=b_{1} b_{2} \ldots b_{n}$ be seculuenes. For a given sequenee $X=a_{1} x_{2} \ldots x_{l}$, we deline the ath predix of $X$, for $i=0,1, \ldots, l$, as $X_{i}=x_{1}, x_{2} \ldots d_{i}$. For example, if $X=$ abedt, then $X_{3}=$ abe and $X_{0}$ is the

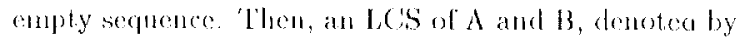
$L C S(A, B)$, can be computed efficiently as the follow ing recursive formula using Dyoumic Programong (for Curther details of ICS, see Thomas II, et. al. 1991).

$$
\operatorname{loc} S^{\prime}(\Lambda, B)=c(m, n)
$$

$$
c(i, j)= \begin{cases}c(i-1, j \cdots 1)+1 & \text { if } a_{i}=b_{j} \\ \max \{c(i, j \cdots 1), c(i-1, j)\} & \text { if } a_{i} \neq b_{j}\end{cases}
$$

where $c(i, j)$ is the length of an bes of the secuences $A_{i}$ and $B_{i}$. If $i=0 \mathrm{and} / \mathrm{or} j=0$, then $c(i, j)=0$. 


\begin{tabular}{c|cccccc}
$c(i, j)$ & $\mathbf{b}$ & $\mathbf{d}$ & $\mathbf{c}$ & $\mathbf{a}$ & $\mathbf{1}$ & $\mathbf{a}$ \\
\hline $\mathbf{a}$ & 0 & $\mathbf{0}$ & 0 & 1 & 1 & 1 \\
b & 1 & 1 & 1 & 1 & 2 & 2 \\
$\mathbf{c}$ & 1 & 1 & 2 & 2 & 2 & 2 \\
$\mathbf{b}$ & 1 & 1 & 2 & 2 & 3 & 3 \\
d & 1 & 2 & 2 & 2 & 3 & 3 \\
a & 1 & 2 & 2 & 3 & 3 & 1 \\
b & 1 & 2 & 2 & 3 & 4 & 1
\end{tabular}

Table 2: Table to Compute LCS of $\mathrm{X}$ and $\mathrm{Y}$

The result of computing LCS is slown as follows.

Fonnally, let $A=a_{1} a_{2} \ldots a_{m}$ and $B=b_{1} b_{2} \ldots b_{n}$ be MMDs. Then, $S(A, B)$ mentioned previously can be defined as follows:

DEF.2: The similarity between MMDs

$$
\begin{gathered}
S(A, B)=\frac{L(S, A, B)^{2}}{m m} \\
(0 \leq S(A, B) \leq 1=S(A, A))
\end{gathered}
$$

Thus, we need not to construct a finite state ant tomaton accepting a set of MMDs and to transform from MMOs to feature vectors. Therefore, the similarity computation based on the I, SS is simpler and easicer than the computation between the vectors.

Batagelj (1989) described that $S(A, B)$ have wat satisfy the following two conditions.

1. $S(A, B)=S(B, A)$

2. $S(A, B) \leq S(A, A)$ or $S(A, B) \geq S(A, A)$

Obviously, the above similarity measure satisfies them.

\subsection{An Experiment}

We now show results of an experiment and verify the similarity measure botween signs. Wo used dala in The Illustrated Sign Diclionary (Marnyama 1981) for the following reasons. Wo made uso the simple description data $(1,527$ entries), which were rendered machine readable data. By merging the same MMDs, in ad vance, 1,514 entries were obtained ${ }^{1}$. For example, 多 角 (name) and バッジ (badge) in Tablo 3 means S( ,バッジ) $=1$.

\footnotetext{
'i.r., nsed pattern matehing conmuandis ark and sed on UNTX
}

The results of an experiment say that the similarities of 36 pairs are greater than 0.8 and 570 pairs are greater

\begin{tabular}{|c|c|c|}
\hline similarity & sign. $\Lambda$ & $\operatorname{sign}, 13$ \\
\hline 0.97 & XIl I (failure) & 济去, 30 (crop) \\
\hline 0.97 & D佾 (aiter) & D年 (besicle) \\
\hline 0.96 & kpi w (klarl) & 沗 T-w (happy) \\
\hline 0.93 & (6it? (work) & TP (iol) \\
\hline 0.91 & 㱙性: (wominn) & ग作 (man) \\
\hline 0.90 & リッパン (emblem) & 多两 (name), \\
\hline 0.88 & 㛄 (danghtor) & $\mathrm{d} J \cdot(\operatorname{son})$ \\
\hline 0.38 & 等滛 (advancement) & |in. $F$ (implovement) \\
\hline 0.88 & 积乔 (intionduce) & 湎歖 (interpreter) \\
\hline 0.87 & leベ (compare) & バランX.B(balance) \\
\hline 0.86 & fitlffil (evidence) & ifil: \\
\hline 0.84 & 楒 & 谱人 $(\mathrm{cry})$ \\
\hline 0.84 & $F \Rightarrow s \%($ go up) & gis (climb) \\
\hline 0.83 & Th (bank) & N (inside) \\
\hline 0.83 & 迷) (hesitate) & 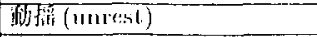 \\
\hline 0.83 & (below) & T:(top) \\
\hline 11.83 & 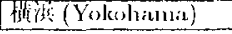 & iff 5 , (trmoodh) \\
\hline
\end{tabular}
than 0.5

Table 3: An lixamplo for Minimal Pairs of Sim

Consider, for example, parts of the approximatesin-

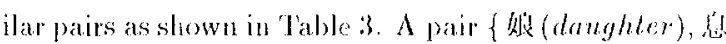

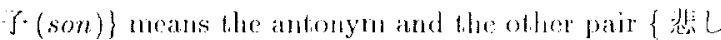

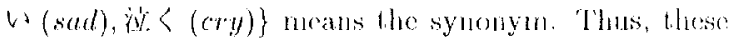
results means that the menbers of a similar pair have the common semantic component. In oller words, by compuning the simblarity of MMT), minimal pairs of signs can bo obtained

The similarity of manual motions results in the similarily of moning, which is a kind of sign formative? units. That is, a minimal pair 煺 and 1 . f have a contnon scmantic component children of parents such as a molion a hand is moved the forward related to the body, and an indiviclual semantic component the female or male sex such as using a little or thumb linger.

'lliere are, lowever, a fow exceptions in the above

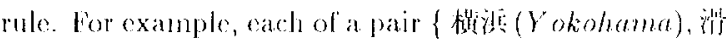
5出 (smooth) \} have different meaning, but both of then are derived from the same iconic motion of the object "razoss". From the language pragmatics points of view, the important thing is that a meaning of signs changes in various context just as a meaning of a word "spring" clanges in various contcext,

The point we wish to mphasize is that comput- 
ing the simblarity between MNOs results the significant. minimal paij of sign.
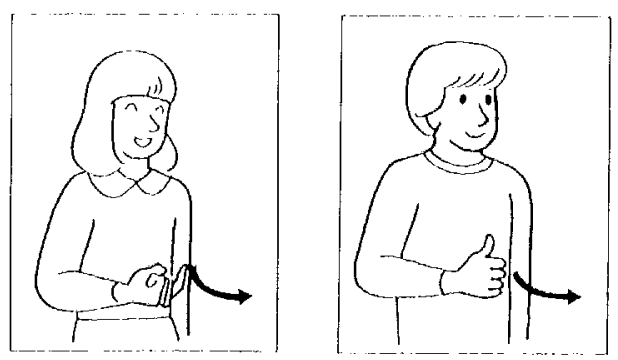

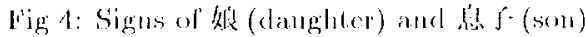

\section{A CIAASSIFICATION METHOD}

\subsection{Mathematical Notion}

For a linite sed $x$, a binary relation $h(X, X)$ that is refleame. symmolric and transithe is called an rquiealenee relation. for each elenent d: in $X$, we define a set. $A_{x}$, which contains all the cloments of $X$ that alre related to $x$ by the cquivalener metation. Formally,

$$
A_{x}=\{y \mid(x, y) \in R(X, X)\} .
$$

$A_{x}$ is clearly a subset of $X$. 'lhe element $x$ is itself contaned in $A_{*}$ due to the reflexivity of $R$; becantse $R$ is transitive and symunetrice, each member of $A_{x}$ is related 10 all the other mombers of $A_{z}$. This set $A_{x}$ is refered to as an equivalence class of $h(X, X)$ with respect to x. The limuly of all such equivalener classess delined by the relation, which is ustanly denoted hy $X / R$, forms a partition on $\mathrm{X}$

\subsection{A Classification Method}

Wo deseribe how elustering a given finite set of signs using the similarity weasure propesed in Section 3. The similarity rolation $S(A, B)$ satislise the following two conditions.

- reflexive: $S(A, A)=1$

- symunctric: $S(A, B)=-S(B, A)$

$S^{\prime}(A, B)$, however, doosn't salisfy the transitive condition. Then, we introduce the following ineguality.

$$
S(A, B) \geq \max \min \{S(A, C), S(C, B)\}
$$

\section{Example 4.1}

Let $X=\{a, b, r, d, c\}$ be a set of signs, and $X \times X=$ $\left\{S^{\prime}(a, a), S(a, b), s^{\prime}(a, c), \ldots, S^{\prime}(r, c)\right\}$.

The similarity relation $S(X, X)$ can be mpresented as

\begin{tabular}{|c|c|c|c|c|c|c|c|c|c|c|c|c|}
\hline$\underline{s}$ & al & b) & c & d & 0 & & 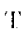 & ia & l, & a: & d & $\theta$ \\
\hline 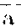 & 1 & 0.2 & 0.5 & 0.3 & 0.8 & & $a$ & 1 & 0.83 & 0.7 & $0 . \overline{3}$ & 0.8 \\
\hline () & 0.2 & 1 & 01.3 & 0.5 & 0.3 & & I, & 0.3 & 1 & 0.3 & 0.5 & 0.3 \\
\hline$c$ & 0.5 & 0.8 & 1 & 0.2 & 0.7 & & t: & 0.7 & 0.33 & 1 & 0.33 & 0.7 \\
\hline d & 0.3 & 0.5 & 0.2 & 1 & 0.2 & & d & 0.3 & 0.5 & 0.3 & 1 & 0.3 \\
\hline e? & 0.8 & 0.03 & 0.7 & 0.2 & 1 & $=-\rightarrow$, & e & 0,8 & (3..3 & 0.7 & 0.3 & 1 \\
\hline
\end{tabular}
the following similarity matrix $S$

S can be transformed inte the above transitive tat trix 'l' by a formula

\begin{tabular}{|c|c|c|c|c|c|c|c|c|c|c|c|}
\hline ]' & & 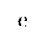 & & I & 1) & & 'I' & a & $t:$ & i: & al \\
\hline & 1 & 0.8 & $\pi .7$ & 0.3 & (1).3 & & a & 1 & 0.8 & $0 . \overline{7}$ & \\
\hline & 0.8 & 1 & 10.7 & 0.3 & 0.3 & & 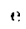 & 0.8 & 1 & 0.7 & \\
\hline & 0.7 & $0 . \bar{t}$ & 1 & 0.3 & 0.3 & & : & 0.7 & 0.7 & 1 & \\
\hline & 0.3 & 0.3 & 0.3 & 1 & 0.5 & & d & & & & 10.5 \\
\hline & 0.3 & 0.3 & 0.3 & 0.5 & 1 & $=\Rightarrow$ & 1, & & & & $\begin{array}{lll}0.5 & 1\end{array}$ \\
\hline
\end{tabular}

$T^{\prime}(A, B)=\max \min \{S(A, C), S(C, B)\}$.

'I' can be transformed inte the other matrix by a matrix sorting operation which rearange the attributes according to their correlation coelficients.

'T'hus, a set, of the sign can be classilied nsing the partition induced by the equivalener gelation $T_{\text {tr }}$ with Whe appropriate threshold $n(1 \geq n \geq 0)$.

$$
\begin{aligned}
& X / T_{1.0}=\{a, b, c, d, c\}, \\
& X / T_{0.8}=\{[a, c], c, d, b\}, \\
& X / T_{0.7}=\{[a, c, c], d, b\}, \\
& X / T_{0.5}=\{[a, c, c],[a, b]\}, \\
& X / T_{0,0}=X / T_{0.3}=\{[a, c, c, d, b]\} .
\end{aligned}
$$

Gonscanonlly, for every monotonically decreasing linite sequences of thresholds $\left(1 \geq \alpha_{1} \geq x_{2} \geq \ldots \geq x_{k} \geq\right.$ 0), the k-tevel herarchy chusters in the form of a clendrogram can be obtained as shown in ligi 5 . However, to construct the dendrogran is not our present purpose. The reason is that the sinularity measure $S(A, B)$ las a feature of the curve $\cos ^{2} \theta$. That is, as the similaritios 
are close the maximum $(S(A, B)=1)$, gains of noise factor (i.e., inflection ) can be ignored. 'Therefore, The low-level clusters $(\leq 0.5)$ are not necessary for our purpose. We want to find the significant sign families than to obtain hicrarchy structures.

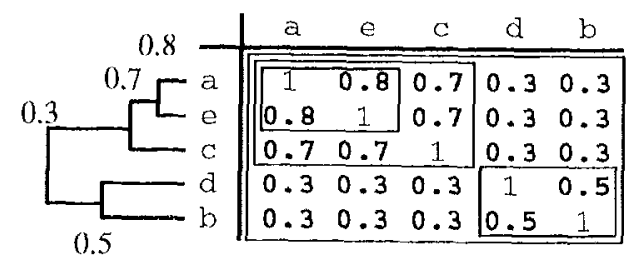

Fig 5: 'J'he $k$-levol hierarchy clusters: dendrogrum

\subsection{An Experiment}

To make discussions simpler, we used the sample data of MMDs (129 entries) including two key-words (characters) of 5 (mouth) 71 ontries and 超 (lips) 58 entries; becanse, a word 笛 can be identified with a word 1.. in Japanese language. We wanted to obtain the results from extracting sign families rather than to obtain the herarchy structure or the form of a dendrogram. The purpose of classifications is to focus on the minimal pairs of signs.

By merging the identical datia that moans $s(A, B)=$ 1, 129 entries are merged into 101 entries. The total amount of sign pairs satisfying $S(A, B) \geq 0.6$ are 25 pairs, and a $31 \times 31$ similarity matrix is obtained. Then, the similarity matrix is transformed into a transitive matrix, and the equivalence classes can be obtained as showu in Table 6.

We classified given signs (129 entries) into 11 clusters and found that the largest amount of sign family is 赤 W(RED)-Canily as follows:

23 entries：赫 (red), 荷: (strawberry), 邀伀 (hered-

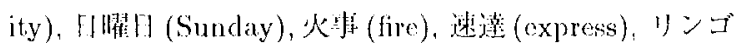

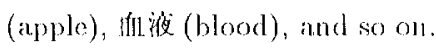

This sign family has an essential common MMD"

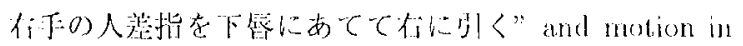
Fig.7, and has semantic component. "red".

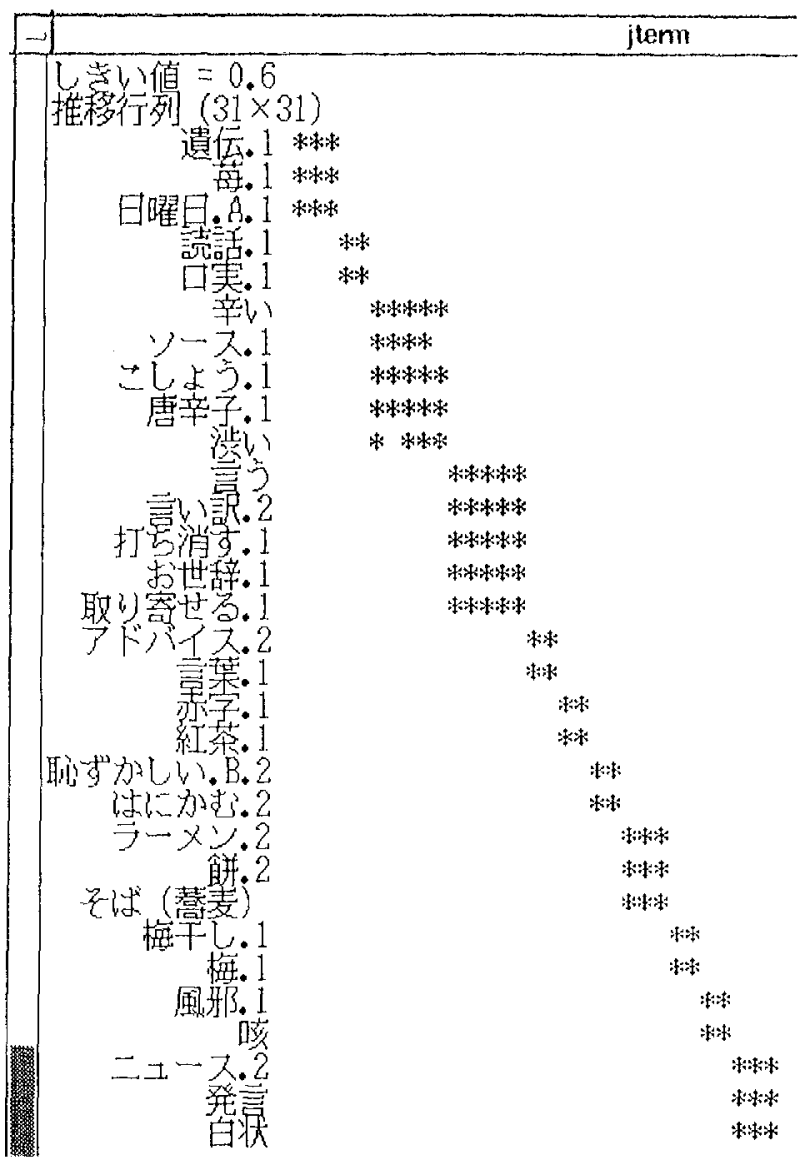

fig 6: A Transitive Matrix

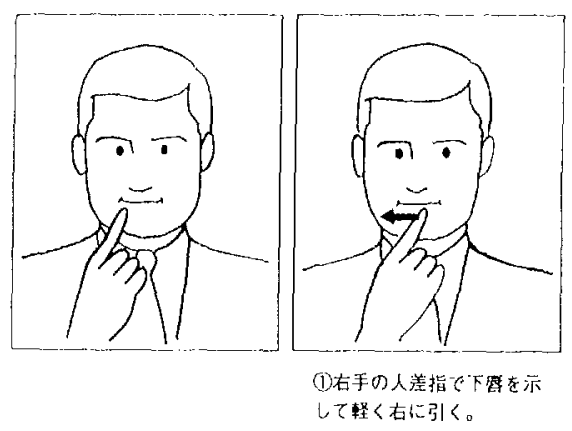

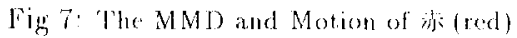


That is, 渞位 (heredity) derived tron "blood", It the H (Sunday) derived from the red mumerie in the calendar, and 速掟 (express) derived from the red-stamp on the letter, and so on.

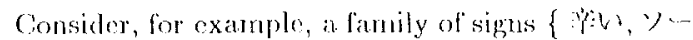

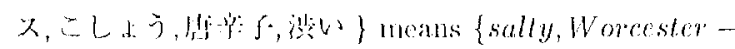
sance, peper, wed-peper, astringent\}. The family las an essential common semantic component, which ancans "uoti sweet" represented as crooking all of lingers. The

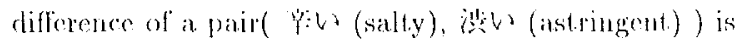
whether to be rotated or un and down.

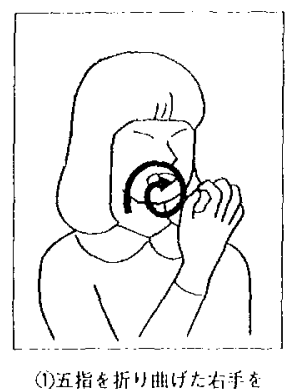

口の前で东打过。

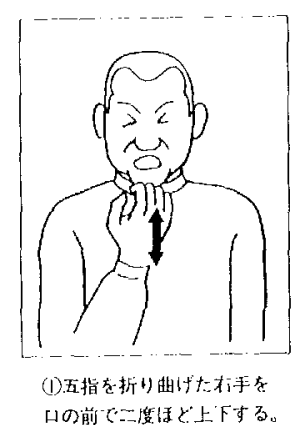

lig 8: Signs of Fin (sally) and 站w (astringent)

\section{CONCLUDING REMARKS}

Wo have proposed a new dassification nethod for signs in JSL. The method is hased on the similarity between the verbal deseriptions of signs, called Manual Motion. Description ( MMI)). 'The similarity of signs can be considered as an internal angle between feature vectors representiod as points in the n-dimensional Buclidean space. By computing fauture vectors of $n$ propotice from MMDs and plotting them in the ndimensional buclidean space, an angle between two vectors can be considered as the similarity between l. he two sigus. As a classification mothod, we have introduced a finite set of signs divided into equivalenee classes on the equivalenee relation with the $k$ level.

As lurther research directions, we will apply this similapily measure to the refrieval of the similar signs in Sign Elcctronic: Dichonary (SED). When wo look al an muknown sign, if the sign motion image can be leperesented using the form of MNIS, the best matched sign or the sign family can be retrieved by computing the similarity anong a given MMI) and MMIss of signs in stils.

\section{ACKNOWIEDGMENTS}

We woukl like tor thank to Dr.'Takeshi Kumagai for reading the manuscript and making a number of helphel suggestions. Wo special thanks are due to a pulslisher hK-Dainamike Seram for permission to peproduce illustrations in Mlustrated Sign Dictionary [10]

\section{REFERENCE}

[1] Stokon,W.C: A Dictionary of American Sign Language on linguistic Principles, finstok Press, 1965.

[2] liricdman,L.A: The manifestation of subject object. and lopis in American Sign language. Acadenic Pross, 1976 .

[3] Battiscon, R,: Lexical borrowing in American Sign language. I,instok Press, 1978.

[1] Kylcol.C: and Woll,B.: Sign tanguage - The study of deaf people and their language, Cambridge University P'ress, 1985

[5] 'lamokant, Takashi. ol al.: S'yawa no Sekai, NIIK Press, 1979 (in japanesie).

[6] Satos Saloshi: CTM:An Lxample-Based translation Aid System. P'rocentings of COLIN('92,1992.

[7] Batagelj,V.: Simalarily Measures between Siructured Objects, MATH/C;LLM/COMP 1988 (Gravale, A. lid), Elsevier, pp. 25-39, 1989.

[8] Aho, A.V., Hoperoft, I.F. and Uhimant,J.I).: The Design and Analysis of Computer Algorilhms, Adkison Wesley, 1971.

[9] 'linomas II, ct al: Introduction to Algorithms, Pp.314-320, MIT Press, 1991.

[10] Marnyama, Ko-ji. Ed: Illustraled Sign Dictionary, KK-Dainamikkı Soraze, 1984 (in lapanesc).

[1]] Ilardigan,.J. A: Chstermy Algorthms, John Wiley, 1971. 

Speech \& Phonology 
